\title{
DEFESA E TRAUMA: DO PROJETO À ATUALIDADE
}

Sissi Vigil Castiel, Alexandra Dal Prá Sibemberg, Luciana Salgado Firpo

e Rosangela Maria Martins da Silva

\author{
Sissi Vigil Castiel \\ Psicanalista, doutora \\ em psicologia \\ pela Universidade \\ Autônoma de \\ Madri, diretora de \\ ensino da Sigmund \\ Freud Associação \\ Psicanalítica de Porto \\ Alegre (SPRGS), \\ autora do livro \\ Sublimação: clínica e \\ metapsicologia (Escuta, \\ 2007).
}

\author{
Alexandra Dal Prá \\ Sibemberg \\ Psicóloga, \\ psicanalista, \\ membro associado \\ do Centro de Estudos \\ Pscicanalíticos de \\ Porto Alegre (CEP de \\ PA), membro efetivo \\ da SPRGS.
}

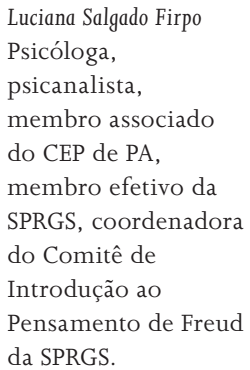

Rosangela Maria Martins

da Silva

Psicóloga,

psicoterapeuta,

especialista em

Psicologia Clínica

pelo Conselho

Federal de

Psicologia, membro

efetivo da SPRGS.
RESUMO: Trata-se de evidenciar, com o estudo do Projeto para uma psicologia científica (1895/1996) de Sigmund Freud, de que forma os postulados da defesa e do trauma aí presentes se articulam com os postulados de Freud sobre a histeria no início de seu trabalho, e qual a sua validade para compreender a psicopatologia na atualidade.

Palavras-chave: Trauma, defesa, histeria, representação.

ABSTRACT: Defense and trauma: from the Project to the present. Through the study of Freud's text Project for a scientific psychology $(1895 / 1996)$, it becomes evident the way in which the statements of defense and trauma are related with Freud's statement about the hysteria at the beginning of his work and what their importance to understand today's psychopathology is.

Keywords: Trauma, defense, hysteria, idea. 


\section{INTRODUÇÃO}

O Projeto para uma psicologia científica (1895/1996) é um texto de referência no estudo da metapsicologia. Ainda que Freud não pensasse dessa forma - pois decide abandoná-lo pouco depois, como nos atesta a correspondência com Fliess, no ano de 1895 (MASSON, 1986). Novamente teve contato com o texto em 1937, por intermédio da Princesa Maria Bonaparte, que o tinha reavido com a compra das cartas Freud-Fliess. Nessa ocasião, queria destruí-lo. Por sorte nossa, não o conseguiu!

O texto só foi publicado 11 anos após a morte de Freud; assim, os psicanalistas, a partir de então, puderam tomar contato com noções que são fundamentos de conceitos posteriores. Assim, torna-se um texto de referência para o estudo da metapsicologia, pois podemos entender aí a origem de muitos conceitos.

Talvez uma das questões mais interessantes do Projeto $(1895 / 1996)^{1}$ seja que Freud parte da observação das neuroses para construir um modelo do funcionamento psíquico em geral, ou seja, sua tentativa de entender a origem da histeria o permite elaborar um projeto do funcionamento psíquico para além da neurose. Assim, diz que todo o psiquismo teria de lidar com quantidades de energia em estado fluente de origem externa e interna. Em suas palavras:

“(...) — na histeria e nas obsessões, nas quais, como veremos, a característica quantitativa surge com mais clareza do que seria normal. Processos como o da estimulação, substituição, conversão e descarga que tiveram de ser descritos ali, sugerem diretamente a concepção da excitação neuronal como quantidade em estado fluente. Pareceria lícito generalizar o que se comprovou ali." (1895/1996, p.347/8)

Freud afirma que as quantidades de energia com as quais um sujeito têm de lidar colocam o psiquismo em funcionamento, pois, das excitações que provêm de fora, o sujeito pode fugir, tal como no modelo do arco-reflexo; entretanto, não se pode fugir das excitações internas, o que acarreta a necessidade de fundar estruturas capazes de dar conta da tramitação interna e descarga adequada das quantidades de energia. A partir disso, descreve um modelo do funcionamento destas estruturas entre si, diferente do que ocorre na patologia neurótica, na qual, além das energias internas, o sujeito tem de lidar com quantidades excessivas provenientes de um trauma. Assim, na citação freudiana, está presente a questão do papel do trauma na origem das neuroses e, ao mesmo tempo, a ideia de que as quantidades de excitação que o sujeito tem de enfrentar põem em funcionamento o psiquismo.

\footnotetext{
${ }^{1}$ Estamos nos referindo ao Projeto para uma psicologia científica (1895/1996), neste trabalho, como Projeto.
} 
Em Neuropsicoses de defesa (1894/1996), escrito um ano antes do Projeto (1895/1996), Freud tinha definido quais eram as consequências psíquicas do trauma e sua implicação para o estabelecimento do sintoma histérico. Em 1895, na primeira parte de seu texto, afirma que seria lícito generalizar que todo o psiquismo tem de lidar com quantidades de estímulos externos como em um trauma, mas também necessita lidar com estímulos internos. A maneira como o infans lida com as quantidades de energia como se defende, e como isto acaba por estruturar o psiquismo é o que será apresentado na primeira parte do texto. A segunda parte se refere a uma análise da histeria fundamentada no destino das quantidades que ingressam a partir do trauma, pensamento que está em conexão com o desenvolvido em Neuropsicoses de defesa (1894/1996) e em textos posteriores.

Na verdade, a formulação freudiana da estruturação do psiquismo a partir da necessidade de lidar com quantidades - o que ele denomina concepção quantitativa - deriva da observação de que na histeria e na neurose obsessiva estão presentes ideias excessivamente intensas: “Deriva-se diretamente das observações clínico-patológicas, sobretudo das relativas a ideias excessivamente intensas — na histeria e nas obsessões, nas quais, como veremos, a característica quantitativa surge com mais clareza do que seria normal.” (FREUD, 1895/1996, p.347)

$\mathrm{Na}$ patologia, as quantidades que ingressam são traumáticas e se tornam incompatíveis com o ego, levando o neurótico a se defender por meio do esquecimento - em seu lugar, formam-se ideias excessivamente intensas. A histérica explica seus sintomas por estas ideias, mas elas, na verdade, não são responsáveis pelos sintomas: são apenas expressões conscientes que estão no lugar do trauma esquecido, o que caracterizaria a defesa patológica. Portanto, poder-se-ia supor que a defesa patológica é o ponto de partida que leva Freud a formular sua concepção dos processos psíquicos em geral. Na primeira parte do Projeto, formula a ideia de uma defesa primária, que se diferencia da patológica porque, nesse caso, o sujeito não lida com quantidades traumáticas. Freud diz que a defesa patológica excede a defesa primária (1895/1996).

Dessa forma, evidencia-se que os conceitos de defesa primária, defesa patológica e trauma são o gatilho que dispara a concepção freudiana do funcionamento psíquico do Projeto. Assim, torna-se importante verificar qual é o estatuto que possuem os conceitos de defesa patológica, defesa primária e trauma no pensamento freudiano de então, bem como estabelecer em que pontos eles fornecem a mola propulsora para o pensamento freudiano posterior. Esse é o objetivo deste texto. 


\section{A DEFESA PATOLÓGICA}

No final do século XIX, Breuer e Freud ultrapassam o pensamento médico da época, outorgando à histeria o estatuto de uma doença psíquica com uma etiologia específica, em contraposição à concepção neurológica da origem desta neurose. Nos Estudos sobre a histeria (1892-1895/1996), demonstram a posição de que, na origem da patologia, existe uma vivência traumática à qual o sujeito não consegue reagir, e isto causa os sintomas da doença. Dessa forma, retiram do quadro o problema da degenerescência orgânica e da lesão. Freud considera a histeria uma doença por representação (1895/1996). Nesta expressão, está em evidência o pensamento freudiano de que a origem da histeria é psíquica.

Dentro desse contexto, em 1896, Freud profere na Sociedade de Psiquiatria uma conferência denominada A etiologia da histeria (1896/1996). Dias depois, conta, em uma carta à Fliess (MASSON, 26 de abril de 1895/1986) que a recepção às suas ideias foi gélida, e que Krafft-Ebing — que presidia a reunião — dissera que aquilo não passava de um “conto de fadas científico” (p.185). Nessa conferência, Freud expressava com clareza sua ideia de que a causa da histeria era prioritariamente psíquica, resultado da impossibilidade de processar no psiquismo um trauma real vivido pelo histérico na área da sexualidade. Entende-se que retirar as questões fisiológicas da etiologia da histeria e situá-la como derivada de uma causa prioritariamente psíquica é o que leva Kraft-Ebing a fazer tal comentário, revelando a ideia de que o estatuto de ciência dos achados teóricos e terapêuticos de Freud adviria de sua proximidade com a fisiologia e a neurologia. No entanto, o pensamento freudiano se distanciou dessa explicação dos fenômenos histéricos.

Em Neuropsicoses de defesa (1894/1996), Freud diferencia seu entendimento do de Janet e Breuer. Pierre Janet, filósofo, atribuía à histeria uma divisão da consciência, como um traço primário devido a uma fraqueza psicológica. Ele nunca levou em conta o recalcamento e rejeitava duramente as formulações de Freud. Breuer entendia que na histeria havia a presença de estados hipnoides que propiciavam que ideias que emergissem ficassem fora da comunicação associativa, acreditando em uma divisão da consciência secundária e percebendo uma falta de reação aos estímulos traumáticos.

Tanto Freud como Breuer partiam do pressuposto de que na base da histeria havia uma experiência real traumática que a originava; por causa dessa situação traumática, havia uma divisão da consciência, mas esta em si não explicava a etiologia da histeria, como afirmava Janet. Pensavam que essa experiência traumática e a lembrança dela causavam um afeto aflitivo. Isso resultava em uma defesa por parte do ego frente à experiência traumática. Diante desse trauma sofrido pelo histérico, fazia-se necessária a retirada da consciência da lembrança desta experiência por meio do esquecimento, o que caracterizaria uma divisão 
da consciência secundária. Esse esquecimento é, então, denominado por eles de recalcamento: esquecer a ideia, retirando o afeto que lhe pertence e deslocandoo para uma inervação somática, por meio do que Freud denomina conversão. A conversão é um símbolo mnésico da experiência traumática recalcada. Na análise do caso de Lucy R., relatado nos Estudos sobre a histeria (1892-1895/1996), Freud diz que o recalcamento constitui a base para a conversão da soma de excitação. Esta última, estando isolada da ideia que foi recalcada, encontra seu caminho até uma inervação somática.

Ainda em Neuropsicoses de defesa (1894/1996), Freud diferencia seu pensamento do de Breuer, afirmando que a natureza da experiência traumática é eminentemente sexual, o que coloca a sexualidade como elemento de origem da histeria. As cenas traumáticas precisam ser recalcadas porque são aflitivas devido a seu conteúdo sexual.

Na segunda parte do Projeto (1895/1996), Freud trata da questão da gênese da histeria, especificando o recalcamento como uma defesa patológica com o caso Emma. Ela está dominada pela compulsão de não poder entrar em lojas sozinha. Como motivo para isso, lembrou-se de que, quando tinha 12 anos, entrou em uma loja, viu dois vendedores rindo juntos e saiu correndo, tomada por uma espécie de susto. Em relação a isso, lembrou que os dois estavam rindo das roupas dela, e que se sentiu atraída por um deles. Freud demonstra, então, que a lembrança é insuficiente para explicar o motivo pelo qual Emma não conseguia entrar sozinha em lojas. Trata-se de uma ideia excessivamente intensa que tem um caráter compulsivo e surge como uma explicação consciente da paciente para o sintoma. O histérico, em geral, está sujeito a uma compulsão exercida por ideias excessivamente intensas. Estas ideias compulsivas são, de início, ininteligíveis, penetram na consciência com demasiada frequência, mas não explicam o porquê da compulsão. Dessa forma, Freud afirma que a ideia excessivamente intensa é substituta de uma ideia original traumática.

Também na análise de Dora (Fragmento da análise de um caso de histeria, 1905/1996a), Freud aborda o papel desempenhado pelas ideias excessivamente intensas, já que ela repetia, de maneira incessante, os mesmos pensamentos sobre as relações do pai com a Sra. K. A respeito disso, a paciente dizia: "não consigo pensar em outra coisa [além da relação do pai com a Sra. K.]” (p.59). Freud mostra que um pensamento oculto (recalcado) encontrava-se por trás dessas ideias, sendo um efeito do processo de recalcamento. Afirma: “Com efeito, o recalcamento muitas vezes se efetua por meio de um reforço excessivo do oposto do pensamento a ser recalcado" (idem, p.60). Em Dora, o que estava recalcado eram os impulsos edípicos em relação ao pai.

A ideia excessivamente intensa é um símbolo. O psiquismo elege este símbolo para administrar o acúmulo de excitação que causa desprazer. No entanto, 
tentando dar conta do que é excessivo, o psiquismo acaba por denunciar a ineficácia de sua solução, pois este mecanismo não garante o esquecimento; a causa é deslocada, mas repetidamente recordada através do símbolo.

O símbolo que a histeria cria é especial, uma vez que não tem uma relação exata com a causa original. Ocorre o isolamento (esquecimento) da causa original que gerou o desprazer, o que constitui o recalcamento como uma defesa patológica, e, em seu lugar, as ideias excessivamente intensas. Para cada compulsão existe um recalcamento correspondente, o que caracteriza a histeria como decorrente de um recalque e da formação patológica de um símbolo. O recalcamento ocorre porque há ideias que fazem parte da vida sexual que despertam no ego um afeto penoso.

Freud, para melhor caracterizar o sintoma histérico no Projeto (1895/1996), utilizou-se do termo Próton Pseudos. Este termo era comumente utilizado na Grécia e indicava que algo que, à primeira vista, parecia ser verdadeiro, todavia não o era; isso levava a desenvolver conclusões equivocadas. Tal termo remete aos Primeiros analíticos de Aristóteles na teoria do silogismo, e tem o objetivo de explicar que uma conclusão falsa é proveniente da falsidade da primeira premissa. Uma vez esta não sendo verdadeira, a conclusão obtida será inevitavelmente falsa, mesmo que o raciocínio usado para esta seja coerente.

Utilizando-se dessa tese aristotélica, Freud pretende demonstrar que, na histeria, as ideias excessivamente intensas que são utilizadas pelo histérico para explicar seus sintomas, tal como em Emma, não são os verdadeiros motivos do sintoma. A representação que vem à consciência precisa ser decifrada, pois ela por si só não é verdadeira, mas uma insinuação da verdade.

A histérica elege para si, por meio do deslocamento, algo que será o substituto do que seria o verdadeiro motivo deste afeto desprazeroso. No caso Emma, Freud prosseguiu em suas investigações, chegando à ideia oculta: aos oito anos de idade, ao entrar em uma confeitaria, fora molestada pelo proprietário. Esta foi a ideia que sofreu o processo de recalcamento. O riso dos vendedores estabeleceu um vínculo associativo com a lembrança do riso do proprietário da confeitaria durante o atentado. Além disso, o proprietário agarrou-lhe por cima das roupas. As roupas e o riso fornecem os elementos para o símbolo que toma o lugar da representação ausente.

Especificando a natureza do trauma, Freud diz que as representações penosas para o ego, que são, por isso, recalcadas, sempre têm cunho sexual. O trauma, portanto, é de natureza sexual. É a sexualidade presente nestas lembranças que gera angústia e, em função disso, precisam ser afastadas da consciência.

As vivências traumáticas aconteceram antes da puberdade, quando não era possível caracterizá-las como de origem sexual. Quando, na puberdade, determinada vivência aciona a recordação do fato vivido no passado, a recordação 
desperta uma liberação sexual que, naquela época, não podia ser liberada e que, no tempo presente, é convertida em angústia. É somente na puberdade que a lembrança adquire, com atraso, o significado traumático. A causa que aciona o distúrbio histérico se mantém, por um tempo, adormecida, como uma imagem mnêmica qualquer, para só mais tarde ganhar um caráter traumático. O fato de Emma se sentir atraída por um dos vendedores aos doze anos é o que permite a ligação associativa com o atentado anterior. Deste modo, a lembrança desperta um afeto que não pôde ser suscitado no passado. A puberdade tornou possível uma interpretação diferente do acontecimento.

Como descreve Garcia-Roza: "Um determinado fato não é traumático no momento que ocorre, mas apenas depois de transformado em lembrança e associado a outro que lhe confere o sentido traumático" (2004, p.191).

Assim, a origem da histeria se situa nas implicações do recalque desta vivência real quando ela adquire um significado traumático. A maneira como o sujeito se defende desta lembrança é recalcando-a, ou seja, convertendo a angústia em sintoma somático.

A eclosão da histeria pode ser invariavelmente atribuída a um conflito psíquico que emerge quando uma ideia incompatível detona uma defesa por parte do ego e solicita recalcamento. A defesa cumpre seu propósito de arremessar a ideia incompatível para fora da consciência. O afeto penoso sentido pelo ego impõe e desencadeia o recalcamento, que provoca o esquecimento, mas não a extinção desta ideia. Sendo assim, a imagem recordativa original não foi apagada: está inserida em um complexo esquema de ocupação que se criou como defesa para evitação do afeto penoso. Cria-se, desta forma, uma resistência extraordinária contra o trabalho de pensar a respeito das representações originais. Quanto maior o recalcamento, maior a compulsão para criar ideias excessivamente intensas, e, com isso, maior a dificuldade de associação destas representações com a causa original. O recalcamento, neste caso, rompe o vínculo, fazendo com que a causa original perca sua capacidade referencial e denotativa. No entanto, na parte I do Projeto (1895/1996), Freud vai diferenciar este tipo de recalcamento-defesa patológica do recalcamento que acontece no funcionamento psíquico em geral, postulando a defesa primária.

\section{A DEFESA PRIMÁRIA}

Para formular o modelo do funcionamento psíquico em geral, além da neurose, Freud (1895/1996) propõe uma concepção quantitativa dos processos psíquicos em que traz duas noções fundamentais: a de neurônio e a de quantidade (Q). A quantidade é a energia que circula pelos neurônios, podendo ser deslocada e descarregada. A energia transita através dos neurônios, que são capazes de 
armazená-la. Por este motivo, um neurônio pode estar ocupado, com uma quantidade de excitação, ou desocupado.

O sistema nervoso recebe estímulos do mundo externo. A tendência é descarregar-se das quantidades de energia que ingressam pela fuga, tal qual o modelo do arco-reflexo. Todavia, o sistema nervoso recebe também estímulos endógenos, que precisam igualmente ser descarregados, e dos quais o organismo não pode se esquivar. Esses estímulos criam as grandes necessidades, tais como a fome, a respiração, a sexualidade, e cessam apenas mediante certas condições que devem ser realizadas no mundo externo. Diante desses estímulos, o aparelho não pode descarregar toda a quantidade de excitação presente no neurônio, pois é necessário que este sustente um acúmulo de Q, em função das ações necessárias para pôr fim aos estímulos.

A partir disso, Freud (1895/1996) diz que a estrutura e o desenvolvimento, assim como as funções dos neurônios, devem ser compreendidos com base no princípio de inércia, que compreende essa tendência a evacuar as quantidades de energia que recebem do mundo externo, com o objetivo de diminuir a excitação presente no neurônio. Com o fracasso desta evacuação de energia diante dos estímulos internos, a tendência do psiquismo passa a ser manter a energia no nível mais baixo possível, o que constitui o princípio de constância. A esse respeito, Castiel afirma:

“Apresenta [Freud] nesse ponto, um dos aspectos de sua genialidade: há um psiquismo com energia e movimento, duas características que são incessantes, inquietantes e perturbadoras, sendo o contrário disto, a morte. Ou seja, a vida está relacionada à tensão, ao desconforto, ao realocar-se, ao mudar de lugar. Aspecto que será retomado em 1919, com a postulação do antagonismo entre Eros e pulsão de morte. Neste, as pulsões de morte inscrevem-se antecedendo e se contrapondo às pulsões de vida que têm como objetivo torná-la inócua. As pulsões de vida se definem por um princípio inverso, o estabelecimento e a manutenção de formas mais organizadas." (CASTIEL, et al., 2009, p.39)

Essa afirmação põe em destaque a questão da necessidade que o sujeito tem de guardar energia dentro de si para pôr fim aos estímulos internos, o que acaba com o programa do princípio de inércia. No início da vida, devido ao estado de desamparo do ser humano, ele por si só não consegue provocar uma ação capaz de diminuir a tensão, resultado do afluxo de excitações endógenas. O objetivo da descarga motora é o alívio da tensão, que só pode ser alcançado se for eliminado o estímulo na fonte (endógena). Enquanto o estado de estimulação não for eliminado ou reduzido, não haverá diminuição da tensão. 
Neste momento, o sujeito precisa ser auxiliado por outro, que realize uma ação para acabar com o estado de tensão. Quando tal ocorre, essa ação diminui a tensão interna, e, assim, surge uma sensação de prazer na consciência. Essa ação é independente da Q endógena, e Freud a chama de ação específica.

A eliminação da tensão decorrente dos estímulos internos possibilitará então o que Freud denomina vivência de satisfação. A vivência de satisfação — só possível pela ação específica - deixa uma marca, e fará com que o sujeito, diante de novo estado de tensão, queira que esta se repita. Portanto, é pela vivência de satisfação que serão construídos os traços mnêmicos, essenciais para o estabelecimento do desejo.

Por meio da vivência de satisfação, devido a um movimento mecânico, a notícia da eliminação da tensão chegará a outros neurônios formando uma trilha, um caminho preferencial entre neurônios que contêm a imagem mnêmica do objeto da satisfação. Quando outra situação de tensão ocorrer, a imagem do objeto é reinvestida, e ocorre algo análogo à percepção, ou seja, uma alucinação. O psiquismo não contém previamente mecanismos internos suficientes para discriminar entre a presença real do objeto da satisfação e a alucinação deste. Assim, torna-se necessário que se adquira um critério para verificar a presença real do objeto da satisfação, a fim de que seja efetuada uma descarga de Q na presença do objeto de desejo, o que efetivamente levaria à satisfação. Do contrário, diante da alucinação, a descarga de Q levaria ao desprazer.

Em continuação a esses postulados, Freud (1895/1996) afirma que as ações humanas se constituem em duas vivências fundamentais: a busca do prazer e a esquiva da dor. As duas ações são vitais para o ser humano, pois é a partir delas que o psiquismo precisará fundar estruturas capazes de chegar à busca do prazer e evitar a dor. A busca do prazer é indicada por Freud como vivência de satisfação. A vivência de dor vem estabelecer a noção de recalcamento.

Tanto na vivência de satisfação quanto na vivência de dor, há uma memória que, em determinadas circunstâncias, é acionada. Na busca do prazer, a imagem do objeto de satisfação é reinvestida. No entanto, para que haja de fato uma satisfação da tensão, o objeto tem de estar verdadeiramente presente.

No caso de um objeto causar dor ao psiquismo, há uma sensação de desprazer, e este aumento quantitativo induz a eliminação da Q para consequente alívio da tensão. Ocorre ainda um trilhamento entre a tendência à descarga e uma imagem-lembrança do objeto que provoca a dor. Se a imagem do objeto hostil é reinvestida, surge um estado de desprazer com uma tendência à descarga. Este estado não é propriamente a dor, mas algo que a ela se assemelha, que Freud chama de afeto (idem). Na recordação da dor há desprazer. O desprazer tem uma origem dupla: no ambiente externo, pelo objeto hostil; internamente, pela recordação. Portanto, evitar a dor terá relação com o não-investimento da 
imagem mnêmica do objeto hostil. Isso é o que Freud (idem) caracteriza como defesa primária: a desocupação da imagem recordativa hostil. A defesa primária, ou recalque, que é acionada no caso da dor, cumpre a função de gerar uma aversão a manter investida a imagem mnêmica hostil. A defesa primária consiste na inversão da corrente de pensamento assim que ela se depara com um neurônio cuja catexia causa desprazer. Portanto, a consequência da defesa primária é gerar prazer, evitando o desprazer.

Freud (idem) afirma que, além da defesa primária, o psiquismo necessita de mecanismos internos para dar conta da insatisfação que seria gerada a partir da recordação da dor e da catexização da imagem mnêmica do objeto da satisfação sem sua presença real. Daí decorre a importância, para a estruturação psíquica, da vivência da dor e do estado de desejo.

Se não existem estruturas internas capazes de inibir o processo alucinatório no caso da dor (catexização da imagem mnêmica do objeto hostil), há a geração de desprazer. Embora o objeto hostil não esteja presente, o desprazer sentido pela representação é como se fosse real e externo. Da mesma maneira, a catexização do objeto de desejo nos estados de desejo leva ao desprazer, pois há uma eliminação da tensão pelos caminhos facilitados, mas não ocorre a satisfação, pois o objeto de desejo não está lá para propiciá-la. Nos estados de desejo, cabe ao ego distinguir entre percepção e representação, e inibir a descarga quando identifica que não se trata de uma percepção, e sim de uma alucinação. Se a inibição, que é tarefa do ego, não se realiza, há naturalmente uma decepção. Dessa maneira, o ego é um conjunto de neurônios que tem por finalidade inibir a descarga da quantidade quando da ausência do objeto da satisfação.

No caso da dor, precisa-se de um signo para a desocupação da imagem recordativa hostil. Essa tarefa do ego se dá pela inibição da descarga de quantidades, pelo processo que Freud denominou de ocupação das vias colaterais, que consiste em inibir a descarga da Q pelos caminhos facilitados, desviando-a para os neurônios colaterais. Se se conseguir realizar a inibição a tempo, não haverá liberação de desprazer — com isto, a defesa será mínima. Porém, no caso oposto, haverá enorme desprazer e defesa primária excessiva. Esse é o papel do ego.

A partir da postulação da inibição da descarga feita pelo ego, Freud (idem) distingue os processos psíquicos primários e os secundários. Os primários correspondem, segundo o modelo biológico, a um momento inicial das histórias do aparelho psíquico. No processo primário, o estado de ligação do ego deixa de ser levado em conta, e prevalecem as ligações associativas criadas pela vivência originária - portanto, a indiferenciação entre percepção e alucinação do objeto. Os processos psíquicos secundários se dão a partir da inibição produzida pelo ego. Nesse caso, verifica-se que a defesa primária é menos utilizada nos processos secundários devido à inibição. 
Aí parece residir a diferença entre defesa primária e defesa patológica. O êxito do recalcamento na histeria diferencia-se muito da defesa primária. Tanto na primeira quanto na segunda, tenta-se evitar pensamentos que geram desprazer, ainda que algumas percepções reavivem a lembrança do que se busca esquecer. No entanto, na histeria, a ideia substituta, a que se torna consciente em lugar daquela que se quer evitar, é uma formação simbólica que constitui a função que excede à defesa normal. O afeto penoso sentido pelo ego impõe o recalcamento, que é diferente daquele que acontece na defesa primária. Ainda que, na histeria, o recalcamento ocasione o esquecimento de uma ideia que leva a um afeto de desprazer, não há a extinção desta ideia. Por isso, a formação do sintoma.

Frente a um acontecimento penoso, a defesa primária é acionada e cumpre a sua função de desocupação da imagem recordativa hostil, que corresponde a uma imagem perceptiva a fim de evitar o desprazer. No caso da histeria, a defesa primária cede lugar à defesa patológica. As duas formas de defesa seguem o mesmo princípio: evitar o desprazer e buscar o equilíbrio das excitações de acordo com o principio de constância. No entanto, na histeria — defesa patológica - o efeito traumático implica a incapacidade do aparelho psíquico de eliminar as excitações de acordo com o princípio de constância, à medida que a lembrança continua existindo, embora deslocada para o símbolo. Já na defesa primária, o aparelho psíquico não investe na imagem do objeto da dor; isto possibilita estar de acordo ao princípio da constância. Na histeria, a defesa primária se torna ineficaz, pois não é possível que ocorra a desocupação da imagem recordativa hostil, uma vez que houve um trauma. O que há de comum entre defesa patológica e defesa primária, que leva Freud a pensar a segunda a partir da primeira, é a questão econômica.

A defesa patológica se figura pela busca de uma solução (embora ineficaz) para o que está estabelecido, elegendo um símbolo que dá o auxílio ao recalcamento, permitindo o escoamento dessas excitações para outros neurônios. O isolamento da causa original não garante o esquecimento, pois ele estará representado em seu deslocamento, sendo o símbolo a marca de sua existência. O patológico, neste caso, é caracterizado pela criação de um símbolo específico, diferente de outros símbolos, por não haver uma relação direta entre o ele e o que visa representar.

\section{TRAUMA}

A questão que se depreende do que foi dito acima é que, no pensamento freudiano dessa época (1895/1996), a necessidade da utilização, por parte do sujeito, de uma defesa patológica se dá frente à existência de um trauma. Do contrário, a defesa primária e a inibição por parte do ego dão conta das Qs. No 
funcionamento psíquico em geral, existem vivências de dor que não têm um caráter traumático. Essas experiências são representadas, e é tarefa do psiquismo defender-se delas não catexizando tais representações, o que constitui a defesa. Assim, pode-se entender a equivalência entre recalcamento e defesa nesse momento do pensamento freudiano. O recalcamento era a maneira de se defender de um conteúdo pulsional aflitivo.

Por outro lado, Freud postulava então que, na histeria, existiam vivências infantis reais na área da sexualidade, as quais só iriam adquirir um significado sexual traumático na puberdade. A partir da significação é que a experiência infantil vai causar angústia, despertando no ego um afeto penoso, e, em função disso será representada e recalcada. Assim, só vai se formar uma neurose porque o trauma vai ser representado, e, por isso, recalcado. O trauma que origina a neurose é, portanto, um trauma que se representa. O recalcamento não pode prescindir da representação. Dentro desse contexto, a angústia desempenha um papel importante, pois ela sinaliza que conteúdo deve ser recalcado. Disso advém a questão de que a neurose é uma possibilidade de inscrição de um padecimento; a partir dessa inscrição, o padecimento pode ser tratado pela psicanálise. Desta maneira, adquirem positividade os conceitos de angústia, sintoma e representação, na medida que a simbolização de um acontecimento traumático do qual se tem notícia pela angústia e pelo sintoma cria possibilidades de dar outros destinos ao sofrimento, e à análise da neurose como forma de recriar a relação do sujeito com o sofrimento. Isso implica dizer que a articulação entre trauma e neurose é fértil.

Ainda que, em 1897, quando Freud declara "não acredito mais em minha neurótica” (MASSON, Carta a Fliess de 21 de setembro de 1897/1986, p.265), tenha desistido da teoria da sedução, não parece que tenha desistido do modelo do trauma. Referia-se exatamente à questão de que não havia sempre vivências sexuais traumáticas na infância dos neuróticos. Essa constatação está relacionada à ideia posterior, presente nos Três ensaios sobre a teoria da sexualidade (1905/1996) e em Dora (Fragmento da análise de um caso de histeria, 1905a/1996), a respeito da existência de uma sexualidade infantil. Assim, essa sexualidade seria recalcada e acompanhada de fantasias que, por seu retorno e impossibilidade de um recalque eficiente, seriam as responsáveis pelo desenvolvimento da neurose.

Desde o ponto de vista das implicações da existência da sexualidade infantil para a conceituação do recalque, as inscrições das experiências de satisfação junto aos objetos externos e internos seriam o que possibilita a representação da pulsão e, ao mesmo tempo, a constituição do inconsciente como um lugar distinto no psiquismo. Assim, o recalque passa a não ser mais somente uma forma de defesa, mas também a maneira de constituição do inconsciente. De qualquer modo, continua existindo uma estreita dependência entre representação e recalque. 
Por outro lado, o posicionamento de Freud em relação à sexualidade infantil acompanhada de fantasias permitia supor que essas últimas seriam as responsáveis pelo desenvolvimento da neurose. O trauma não seria necessariamente real e pode ser o modelo do padecimento que consegue se transformar em neurose porque se representa, permanece e define o que seria uma estrutura neurótica. Portanto, a ideia de que um sujeito se defende de um trauma a partir de sua inscrição, presente no Projeto, implica pilares sólidos para a psicopatologia.

Freud vai desenvolver a ampliação do conceito de trauma a partir de 1920, em Além do princípio do prazer (1920/1996), constatando que existem situações na vida psíquica que colocam em cheque o princípio de prazer. Fixa-se, a partir desta época, a ideia de que o trauma decorre de uma quantidade de energia que ingressa no aparelho psíquico, e que não existem inscrições de cenas que possam ligar esta energia que invade o psiquismo, impossibilitando que esta venha a se transformar em inscrições e representações.

A ausência de representação cria um desequilíbrio de forças dentro do psiquismo, de modo que a tendência é de funcionar em nível de processo primário, para descarregar-se da energia excessiva. Conforme Valls (sd), o que fica do trauma é uma facilitação no aparelho psíquico, que leva a repetir a experiência traumática; por outro lado, há a necessidade de contrainvestimentos defensivos, que produzem fixações e, em consequência, também tendem a repetir-se. Ocorre que, neste caso, não há uma tendência a agir como uma maneira de dar um significado ou sentido àquelas situações. O sujeito age simplesmente com o intuito de descarregar o máximo possível de energia.

A concepção de trauma em 1920 se difere da concepção do trauma que gera a neurose, porque na primeira não existe a possibilidade de uma cena posterior significar o acontecimento traumático, tornando possível a representação. O que não tem representação não tem significação e também não gera angústia-sinal. As quantidades excessivas são descarregadas na ausência da representação do objeto da satisfação. Com isso, não há ligação no sentido da retenção (inibição) da energia, o que indica um funcionamento em nível de processo primário e ausência do princípio do prazer. Assim, a ação do sujeito é para efetuar a descarga da quantidade de energia, pois não há objeto de satisfação presente. Isso leva ao desapontamento frente à ação. Esse processo caracteriza a passagem ao ato, tão frequente nas patologias da não-representação.

Pode-se dizer que o circuito pulsional que se institui a partir da experiência de satisfação — descrita no Projeto (1895/1996) — as inscrições e representações, e o estabelecimento do princípio do prazer e do processo secundário que daí advém, permitem o recalque como defesa diante do pulsional. Ambas as formulações — a de 1895 e a de 1920 — constituem duas naturezas distintas 
da situação metapsicológica e, portanto, duas possibilidades psicopatológicas diferentes: neurose e patologias da não-representação.

Desde esta perspectiva da conceituação posterior de trauma — impossibilitado de representação - o tratamento consiste, então, em formar marcas mnêmicas, representações. Existiria uma primeira etapa do tratamento, que diria respeito a uma simbolização. De fato, só o entendimento da problemática do não-representado é que possibilita a Freud teorizar a respeito do papel da simbolização e da representação na análise (BIRMAN, 1991). Dentro desse contexto, Castiel (2007) destaca o papel do analista como aquele que — pela transferência — se constitui como objeto para a pulsão, de forma que as forças pulsionais possam ser representadas.

Roussillon (2006) aborda, de forma muito pertinente, a questão da necessidade de construção do traumatismo em patologias severas. Para o autor, esse trabalho se constitui em objetalizar o trauma. Entende-se que a perspectiva de Roussillon se refere à transformação do trauma da ausência de representação no trauma inicial de Freud, enfatizando a importância da marca, do traço mnêmico do objeto para poder haver uma representação. Dentro desse contexto, o autor introduz a ideia de que esse tipo de traumatismo (das patologias severas) é psíquico/ pré-psíquico. São traumas que implicaram efeitos psíquicos sobre a estruturação do psiquismo, mas são também pré-psíquicos, na medida que o psiquismo não pode organizar uma representação de seu impacto. Essa formulação de Roussillon também permite colocar em destaque o papel da simbolização como meta inicial do tratamento das patologias mais severas, para se constituir um inconsciente recalcado, e somente a partir daí, aproximar o trabalho da abordagem clássica da transformação da representação-coisa em representação-palavra.

Enfim, entende-se que o modelo do trauma é atual no que diz respeito à técnica analítica; serve de parâmetro para a análise de patologias mais severas, quando se torna necessário um trabalho de simbolização. Neste panorama, o modelo do trauma adquire toda a sua positividade, pois a representação depende de traços de objeto, ideia presente nesse padrão.

Recebido em 2/8/2009. Aprovado em 22/2/2010. 


\title{
REFERÊNCIAS
}

BIRMAN, J. (1991) Freud e a interpretação psicanalítica. Rio de Janeiro: RelumeDumará.

CASTIEL, S. (2007) Sublimação: clínica e metapsicologia. São Paulo: Escuta. et al. (2009) Freud e o projeto da psicanálise, Revista da Sociedade de Psicologia do Rio Grande do Sul, v.8, n.1, Porto Alegre.

FREUD, S. (1996) Edição standard das obras psicológicas completas. Rio de Janeiro: Imago.

(1893) “Sobre os mecanismos psíquicos dos fenômenos histéricos: uma conferência”, v.3, p.35-47.

(1894) "As neuropsicoses de defesa", v.3, p.51 a 72.

(1892-1895) "Estudos sobre a histeria”, v.2, p.13 a 321.

(1895) "Projeto para uma psicologia científica”, v.1, p.335 a 455.

(1896) “A etiologia da histeria”, v.3, p.187 a 215.

(1905a) "Fragmento da análise de um caso de histeria”, v.7, p.15 a 116.

(1905) “Três ensaios sobre a teoria da sexualidade", v.7, p.119 a 231.

(1920) “Além do princípio do prazer", v.18, p.13 a 75.

GARCIA ROZA, L. A. (2004) Introdução à metapsicologia freudiana: sobre as afasias, v.1. Rio de Janeiro: Jorge Zahar.

LAPLANCHE, J. e PONTALIS. (1992) Vocabulário da psicanálise. São Paulo: Martins Fontes.

MASSON, J. (1986) A correspondência completa de Sigmund Freud para Wilhelm Fliess 1887-1904. Rio de Janeiro: Imago.

ROUSSILLON, R. (2006) Paradoxos e situações limites da psicanálise. São Leopoldo: Editora Unisinos.

VALLS, J.L. (s/d) Diccionario freudiano. Madri: Julian Yebenes.

\author{
Sissi Vigil Castiel \\ scastiel@terra.com.br \\ Alexandra Dal Prá Sibemberg \\ xandadalpra@hotmail.com \\ Luciana Salgado Firpo \\ lucianafirpo@terra.com.br \\ Rosangela Maria Martins da Silva \\ ro4@terra.com.br
}

